\title{
Improvement of comprehensive performance of compound green soil in sponge city
}

\author{
Lei Zhang ${ }^{{ }^{\dagger}}$, Zhicheng Li ${ }^{1}$, Tianliang Yang ${ }^{3}$, Ping Yang ${ }^{1,2}$ \\ ${ }^{1}$ Department of Ceotechnical Engineering, College of Civil Engineering, Tongji University, Shanghai 200092, China \\ ${ }^{2}$ Key Laboratory of Geotechnical and Underground Engineering of Ministry of Education, Tongji University, Shanghai 200092, China \\ ${ }^{3}$ Key Laboratory of Land Subsidence Monitoring and Prevention, Ministry of Natural Resources, Shanghai 200092, China
}

\begin{abstract}
Large-scale constructions of urbanization increase the impervious areas of city, leading to the urban hydrological effects such as urban waterlogging and rainwater runoff pollution. To this end, China proposed to adopt the measure to build sponge cities. However, the existing green soil cannot meet the comprehensive needs of sponge city. In order to quickly evaluate the comprehensive performance of the soil in sponge city, a comprehensive evaluation criterion was designed, which is related to the characteristics of greening soil permeability, porosity, $\mathrm{pH}$, salinity and fertility. Based on the criterion, a new type of composite green soil was obtained with the silt soil: medium sand: sawdust ratio of $72.5 \%: 20 \%: 7.5 \%$. Finally, compared with the existing soil, the new green soil not only meets the comprehensive performance requirements of the green soil's fertility, $\mathrm{pH}$, permeability and other factors, but also has higher permeability and water retention. It was proved that the new green soil has apparent advantages in the control of rainwater.
\end{abstract}

Keywords: Compound green soil, Comprehensive performance, Evaluation criterion, Improvement, Sponge city

\section{Introduction}

After decades of development, the urbanization construction in China has made great achievements, and megacities such as Shanghai are leading the country and developing rapidly [1, 2]. However, influenced by the increase in large-scale urbanization construction, a large increase in impervious areas has led to significant urban hydrological effects, including urban waterlogging and rainwater runoff pollution [3-5]. To solve a series of urban problems caused by the urbanization process, China proposed to build sponge city with natural accumulation, natural penetration and natural purification based on LID technology [6]. The sponge city mainly realizes the benign hydrological cycle of the city by various technical means such as "seepage, stagnation, storage, purification, use and drainage", thereby improving the ability of penetration, storage, purification, utilization and discharge of runoff rainwater [7]. As essential sponge facilities in the construction of sponge cities, green roofs, rain gardens, sunken green spaces, artificial soil infiltration, etc. have high requirements on soil [8-13]. Therefore, the green soil in the sponge city plays a particularly

This is an Open Access article distributed under the terms of the Creative Commons Attribution Non-Commercial License (http://creativecommons.org/licenses/by-nc/3.0/) which permits unrestricted non-commercial use, distribution, and reproduction in any medium, provided the original work is properly cited.

Copyright (C) 2021 Korean Society of Environmental Engineers important role in its construction.

The green soil in the sponge city not only needs to meet the basic needs of greening plants, but also to make the rain quickly infiltrate when the heavy rain comes. Besides, the capacity of soil should hold a certain amount of water in a short time to stagger the peak runoff time and improve the management and control of rainwater. Therefore, the soil should have high permeability, high water holding capacity, high aeration porosity and high fertility $[14,15]$. However, with the rapid development of various municipal and civil engineering constructions, urban green soil at the stage has experienced serious compaction and degradation. It features low permeability, poor structural morphology, high levels of foreign matter and low organic matter content [16-20]. These features are conducive to neither the infiltration and drainage of urban rainwater, nor the growth of green plant. Moreover, the current greening soil cannot fully exert the benefits of the sponge city's facilities for rainwater management. Therefore, to enhance the efficiency of sponge cities, it is urgent to improve the current urban green soil.

At present, many scholars have conducted extensive and in-depth investigations and studies on the improvement of green soil in

Received July 03, 2020 Accepted September 09, 2020

${ }^{\dagger}$ Corresponding author

Email: 1830165@tongji.edu.cn

Tel: +86 15116110004 Fax: +086 09231092

ORCID: 0000-0003-0568-7334 
sponge cities. For permeability, Wei et al. (2010) [21] pointed out that edible fungus residue can improve soil and increase soil permeability. Besides, Tian et al. (2011) [22] verified this conclusion experimentally. Wei et al. (2011) [23] used soil, medium sand, hot metal slag, and sawdust to improve the soil infiltration rate. Besides, Zhu et al. (2013) [24] added 5\% humus soil and 15-35\% sand to the red loam soil, which has significantly improved soil permeability. For soil fertility, Shen et al. (2011) [25] studied the improvement of soil fertility by using waste diatomite through field leaching. It was found that waste diatomite had a significant effect on improving soil fertility and its reasonable amount was 5.2-6.0\% of soil content. For water holding capacity, Chu et al. (2017) [26] pointed out that the ratio of soil to sand affects the water holding capacity. When the ratio of sand to the soil is 1 : 2, 1: 1 , and 2: 1 , the total amount of soil water storage decreases in turn. For removing contaminants, Jing et al. (2019) [27] designed a high $\mathrm{NH}_{3}-\mathrm{N}$ removal urban sponge for application in red soils, which also has high permeability.

The researches mentioned above have laid a solid foundation for the improvement of green soil in sponge cities. However, most of them focused on one or two aspects of research, failing to comprehensively consider the physical and chemical parameters of the soil so that the researches are more one-sided. The requirements of the sponge city for soil include various factors such as high permeability, high water holding capacity, suitable $\mathrm{pH}$ and high fertility. Therefore, a new type of greening soil of the sponge city should be designed, which can meet the all requirements of soil fertility, permeability, $\mathrm{pH}$, and water holding capacity. This new type of soil could be prepared by adding sand and improved materials to the silt soil in a certain proportion.

This study aims to design an evaluation criterion that can quickly evaluate the comprehensive performance of green soil. Besides, it also aims to design a new type of composite green soil with high permeability, high water holding capacity and high fertility. Moreover, the study compared the comprehensive characteristics of the new greening soil with other existing soil to demonstrate the superiority of the new greening soil.

\section{Materials and Methods}

\subsection{Formulation of the Evaluation Criterion}

According to the relevant design requirements ("Greening Planting Soil" (CJ/T340-2016), "Garden Greening Planting Soil Quality Specification" (DG/TJ08-231-2013)), the greening soil should have the characteristics of high permeability, high water holding capacity, good aeration porosity, high fertility and suitability of plant growth. Moreover, in the process of controlling rainwater in sponge cities, the greening soil is required to have high permeability and good water holding capacity. It was proved that the water holding capacity of soil and bulk density have the good correlation with total porosity [28-30]. Therefore, six parameters of permeation rate, total porosity, aeration porosity, $\mathrm{pH}$, salt content and organic matter content were selected as soil characteristic parameters. In the case involving six parameters, in order to quickly evaluate the quality of green soil in sponge city, an evaluation criterion was established and a comprehensive quantitative index was defined. Besides, the six parameters were graded according to the numerical range and given corresponding scores.

For the evaluation criterion, firstly, according to the relevant norms or academic research conclusions, the basic limit line of each parameter was obtained, which was the pass line. Secondly, the value corresponding to the pass line was changed by about $10 \%$ or take an integer to change the grading level accordingly, so as to complete the division of the evaluation standard system. Then, in each parameter score, 1 point is the lowest score and the highest score is 5 points. Specifically, 3 points are the lowest value that meets the relevant norms or scholars' research conclusions, which is defined as a passing score. The result of exceeding the limit of the relevant norm or scholar's research conclusion is 1 point, and the result of the highest degree of agreement with the relevant norm or scholar's research conclusion is 5 points.

\subsubsection{Permeation rate}

According to the relevant specification ("Greening Planting Soil" (CJ/T340-2016)), the penetration rate is required between $2.78 \times$ $10^{-6} \mathrm{~m} / \mathrm{s}$ and $100 \times 10^{-6} \mathrm{~m} / \mathrm{s}$. Therefore, the result of less than $2.78 \times 10^{-6} \mathrm{~m} / \mathrm{s}$ or more than $100 \times 10^{-6} \mathrm{~m} / \mathrm{s}$ is 1 point. The saturated stable penetration rate of compound greening soil was set to $5.56-14 \times 10^{-6} \mathrm{~m} / \mathrm{s}$. The rate of $5.56 \times 10^{-6} \mathrm{~m} / \mathrm{s}$ is twice the required minimum value of $2.78 \times 10^{-6} \mathrm{~m} / \mathrm{s}$, which was increased by $10 \%$ to obtain an integer of $6 \times 10^{-6} \mathrm{~m} / \mathrm{s}$. Further, the penetration rate score of $5.56-6 \times 10^{-6} \mathrm{~m} / \mathrm{s}$ is 3 points. In addition, the penetration rate of $14 \times 10^{-6} \mathrm{~m} / \mathrm{s}$ has an excellent treatment rate of stormwater accumulation. Meanwhile, considering the relationship between the penetration rate and the water holding capacity, the result of $2.78-5.56 \times 10^{-6} \mathrm{~m} / \mathrm{s}$ or $14-100 \times 10^{-6} \mathrm{~m} / \mathrm{s}$ divided into 2 points. Moreover, $7 \times 10^{-6} \mathrm{~m} / \mathrm{s}$ is the conclusion that the greening soil has good penetration effect and purification effect. Therefore, the result of $6-7 \times 10^{-6} \mathrm{~m} / \mathrm{s}$ is 4 points. Finally, for the better permeability, the result of $7-14 \times 10^{-6} \mathrm{~m} / \mathrm{s}$ is 5 points.

\subsubsection{Total porosity}

According to the Eq. (1), the total porosity was calculated as 51\% when the bulk density of the soil was $1.3 \mathrm{~g} / \mathrm{cm}^{3}$ (average bulk density of natural soil); $49 \%$ when the $1.35 \mathrm{~g} / \mathrm{cm}^{3}$ (hinders plant growth when greater than $1.35 \mathrm{~g} / \mathrm{cm}^{3}$ ). Besides, when the total porosity is more than $50 \%$, it is suitable for the green plant, and $50 \%-56 \%$ is the best. However, when it is more than $60 \%$, it is not suitable as green soil [31]. Then, $50 \%$ was decreased by $10 \%$ to get the critical line of $45 \%$, so the result of less than $45 \%$ or more than $60 \%$ is 1 point and $49-50 \%$ result is 3 points. Moreover, the result of $45-49 \%$ or $56-60 \%$ is given as 2 points. In the end, the result of $50-51 \%$ is 4 points, and $51-56 \%$ is 5 points.

$$
n(\%)=\left(1-\rho_{b} / \rho_{s}\right) \times 100 \%
$$

where $\rho_{s}$ is the Soil particle density, and it usually takes the value of $2.65 \mathrm{~g} / \mathrm{cm}^{3}$.

\subsubsection{Aeration porosity}

It is great when the aeration porosity is more than $10 \%$, and $15-20 \%$ is better [16, 31]. Moreover, according to relevant specifications ("Garden Greening Planting Soil Quality Specification" 
(DG/TJ08-231-2013)), 8\%, 10\% and 15\% are the requirements for aeration porosity under different planting conditions. Therefore, the result of less than $8 \%$ or more than $20 \%$ is 1 point. Taking into account the correlation between water holding capacity and aeration porosity [32], a $10 \%$ reduction in aeration porosity of $20 \%$ could give a limit line of $18 \%$. Then, the result of $8-10 \%$ or $18-20 \%$ is 2 points. In addition, increasing $10 \%$ by $10 \%$ results in a limit line of $11 \%$. Thus, the result of $10-11 \%$ is 3 points. Finally, the result is $11-15 \%$ for 4 points and $15-18 \%$ for 5 points.

\subsection{4. $\mathrm{pH}$}

According to the different test methods in the specification ("Greening Planting Soil" (CJ/T340-2016)), it is required between 5.0 and 8.3 in the water-soil ratio method and 5.0-8.0 in the saturation method. Besides, the score of $\mathrm{pH}$ also needs to be based on the characteristics of the plant being planted. In the absence of specific planting conditions, this system does not consider the range of 4 points and 5 points. Finally, according to the general range, the result of less than 5 or more than 8.3 is 1 point; the result of $5-5.5$ or $8-8.3$ is 2 points and $5.5-8.0$ is 3 points.

\subsubsection{Salt content}

It is not conducive to plant growth when the soil salt content exceeds $1,000 \mathrm{mg} / \mathrm{kg}$. Besides, according to the norm ("Geotechnical Engineering Investigation Code" (GB50021-2001)), it would have a negative impact on plant growth when the soluble salt content is between $3000 \mathrm{mg} / \mathrm{kg}$ and $10,000 \mathrm{mg} / \mathrm{kg}$. Therefore, the result is 1 point for more than $10,000 \mathrm{mg} / \mathrm{kg} ; 2$ points for $1,000-10,000$ $\mathrm{mg} / \mathrm{kg}$. Then, $1,000 \mathrm{mg} / \mathrm{kg}$ was reduced by $10 \%$ and $20 \%$ in turn to get $900 \mathrm{mg} / \mathrm{kg}$ and $800 \mathrm{mg} / \mathrm{kg}$, respectively. Finally, the result of $900-1,000 \mathrm{mg} / \mathrm{kg}$ is 3 points; $800-900 \mathrm{mg} / \mathrm{kg}$ is 4 points, and the result of less than $800 \mathrm{mg} / \mathrm{kg}$ is 5 points.

\subsubsection{Organic matter content}

According to the specification ("Greening Planting Soil" (CJ/T340-2016)), the basic organic matter content of the greening soil is $12-80 \mathrm{~g} / \mathrm{kg}$. Moreover, considering the fertility of the greening soil, it is required that the organic matter content should be 20-80 $\mathrm{g} / \mathrm{kg}$. The organic matter content of $25 \mathrm{~g} / \mathrm{kg}$ could meet the basic requirements given in planting situations. Organic matter content at $35-80 \mathrm{~g} / \mathrm{kg}$ meets the various planting conditions specified in the specifications, so the highest score. Therefore, the result of less than $12 \mathrm{~g} / \mathrm{kg}$ or more than $80 \mathrm{~g} / \mathrm{kg}$ is 1 point; $12-20 \mathrm{~g} / \mathrm{kg}$ is 2 points; $20-25 \mathrm{~g} / \mathrm{kg}$ is 3 points; $25-35 \mathrm{~g} / \mathrm{kg}$ is 4 points, and $35-80$ $\mathrm{g} / \mathrm{kg}$ is 5 points.

\subsubsection{The evaluation criterion}

According to the results of the above parameter standards, the comprehensive performance evaluation criterion of green soil was finally obtained, as shown in Table 1 . Based on the evaluation criterion, the comprehensive score $\beta$ of greening soil could be calculated. Then, $\beta$ is the sum of 6 sub-items, and each sub-item score has the same weight. The larger the value, the better the quality of the greening soil. If any two or more of the 6 sub-items are less than 3 points, it is determined that the sample does not meet the relevant engineering and technical requirements.

The value standard of this system refers to the Scholar's research conclusions and the urban construction standard promulgated by the State Housing and Urban-rural Construction Bureau, and their application scope is very wide. Meanwhile, the problems of serious compaction, poor fertility, and low permeability of urban green soils are widespread in most parts of China. Therefore, the evaluation criterion is applicable in most areas of China.

\subsection{Silt Soil}

Silt soil was obtained from the Shanghai green belt through a series of processes such as air drying, impurity removal and screening. Finally, the air-dried soil with a particle size of less than $2 \mathrm{~mm}$ was obtained. The particle gradation is shown in Table S1.

\subsection{Medium Sand}

Medium sand is the air-dried sand with the particle size of less than $2 \mathrm{~mm}$, which was obtained through a series of processes such as drying, impurity removal, and screening after being retrieved from the river sand. Its particle gradation is shown in Table S2.

\subsection{Improved Materials}

For improved materials, diatomite has strong water absorption, stable physical and chemical properties. The use of dynamite could improve the function of water and fertilizer retention in green soil [33, 34]. Moreover, blast furnace slag has strong water absorption and decontamination ability. Adding blast furnace slag to the soil could significantly improve the permeability of soil [35]. Sawdust could not only improve the structure of soil, but also could provide biological nutrients. It was proved that sawdust could improve

Table 1. Evaluation Criterion for Comprehensive Performance of Green Soil

\begin{tabular}{|c|c|c|c|c|c|}
\hline Item Score & 1 & 2 & 3 & 4 & 5 \\
\hline Penetration rate $\left(\times 10^{-6} \mathrm{~m} / \mathrm{s}\right)$ & $<2.78$ or $>100$ & $2.78-5.56$ or $14-100$ & $5.56-6$ & $6-7$ & $7-14$ \\
\hline Total porosity (\%) & $<45$ or $>60$ & $45-49$ or $56-60$ & $49-50$ & $50-51$ & $51-56$ \\
\hline Aeration porosity (\%) & $<8$ or $>20$ & $8-10$ or $18-20$ & $10-11$ & $11-15$ & $15-18$ \\
\hline $\mathrm{pH}$ & $<5$ or $>8.3$ & $5-5.5$ or $8.0-8.3$ & $5.5-8.0$ & $-*$ & $-*$ \\
\hline Salt content (mg/kg) & $>10,000$ & $1,000-10,000$ & $900-1,000$ & $800-900$ & $<800$ \\
\hline Organic matter content (g/kg) & $<12$ or $>80$ & $12-20$ & $20-25$ & $25-35$ & $35-80$ \\
\hline
\end{tabular}

* "-" means the corresponding grade score needs to be given according to the specific plants. 
soil permeability and maintain green soil moisture [36, 37]. The mushroom residue is rich in various nutrients and could be applied to the soil after high-temperature compost treatment to improve the soil structure [38, 39].

Therefore, this study used four added materials: diatomite, blast furnace slag, sawdust and mushroom residue. The diatomite and the blast furnace slag are powdered. Meanwhile, the sawdust is camphor wood sawdust, accounting for $79.9 \%$ of the sawdust whose particle size is less than $1 \mathrm{~mm}$ and $20.1 \%$ of the sawdust whose particle size is $1-2 \mathrm{~mm}$. The particle size of the selected mushroom residue is less than $2 \mathrm{~mm}$, as shown in Fig. S1.

\subsection{Experimental Scheme}

(1) The sand and silt soil uniformly were stirred according to 1: 4 [22].

(2) The mixed soil was divided into four major groups A, B, $\mathrm{C}$, and $\mathrm{D}$. Then, the added materials respectively are diatomite, blast furnace slag, sawdust and mushroom residue. Each major group was set with 4 improved material addition ratios. Besides, each ratio is a small group, and each small group is set with 4 samples. Namely, there were a total of 4 major groups, 16 small groups and 64 samples, as shown in Table 2.

(3) The characteristic parameters of each small group were measured: stable permeation rate, total porosity, aeration porosity, $\mathrm{pH}$, salt content and organic matter content.

Firstly, according to the specification ("Determination of Forest Soil Permeability" (GB/T 7838-1987)), the stable permeation rate was measured by the cutting ring method, and the soil samples were fully saturated and then tested. Then, according to the Eq. (1), the total porosity could be calculated. Besides, for the aeration porosity, according to specification (Forest soil moisture-determination of physical properties (LY/T 1215-1999)), it could be by Eq. (2). Among them, the maximum water holding capacity and field water holding capacity could be obtained through immersion saturation test and drainage test.

$$
n_{t}(\%)=\left(w_{z}-w_{t}\right) \times \rho_{b} / \rho_{w} \times 0.1
$$

where $w_{z}$ is maximum water holding capacity; $w_{t}$ is field water holding capacity; and $\rho_{W}$ is water density.

The $\mathrm{pH}$ and salt content were directly measured by the $\mathrm{pH}$ meter and TDS meter provided by the soil nutrient quick tester (HM-TYA). In addition, the organic matter content was measured by the soil nutrient quick tester (HM-TYA) through the principle of colorimetry.

(4) The comprehensive score $\beta$ of green soil in each group were calculated. Then, the optimal group was determined according to the $\beta$, and then the best improved material was determined.

(5) The medium sand addition ratio of the optimal group was changed. From the subsequent test results in Table 4, the C2 and C3 groups were the optimal groups. Therefore, the medium sand addition ratios are respectively set to $15 \%, 20 \%$ and $25 \%$. Finally, the two major groups called $\mathrm{E}$ and $\mathrm{F}$ were set up, each major group has three small groups, and each small group has four samples. Namely, a total of two major groups, six small groups and 24 samples were set up, as shown in Table 3.

(6) The characteristic parameters of each group were measured: stable permeation rate, total porosity, aeration porosity, $\mathrm{pH}$, salt content and organic matter content. The measurement methods were the same as that of the third step mentioned above.

(7) The comprehensive score $\beta$ of green soil in each group were calculated, and the optimal group was determined.

Table 2. Test Ratio Setting of Samples in Groups A, B, C and D

\begin{tabular}{|c|c|c|c|c|c|c|c|}
\hline Group & Soil (\%) & Sand (\%) & Improved material (\%) & Group & Soil (\%) & Sand (\%) & Improved material (\%) \\
\hline A1 & 77.5 & 20 & 2.5 & C1 & 77.5 & 20 & 2.5 \\
\hline $\mathrm{A} 2$ & 75 & 20 & 5 & $\mathrm{C} 2$ & 75 & 20 & 5 \\
\hline A3 & 72.5 & 20 & 7.5 & C3 & 72.5 & 20 & 7.5 \\
\hline A4 & 70 & 20 & 10 & $\mathrm{C} 4$ & 70 & 20 & 10 \\
\hline B1 & 77.5 & 20 & 2.5 & D1 & 77.5 & 20 & 2.5 \\
\hline B2 & 75 & 20 & 5 & D2 & 75 & 20 & 5 \\
\hline B3 & 72.5 & 20 & 7.5 & D3 & 72.5 & 20 & 7.5 \\
\hline B4 & 70 & 20 & 10 & D4 & 70 & 20 & 10 \\
\hline
\end{tabular}

Table 3. Test Proportion Setting of Group E and F

\begin{tabular}{lccc}
\hline Group & Soil (\%) & Sand (\%) & Sawdust (\%) \\
\hline E1 & 80 & 15 & 5 \\
E2 & 75 & 20 & 5 \\
E3 & 70 & 25 & 5 \\
F1 & 77.5 & 15 & 7.5 \\
F2 & 72.5 & 20 & 7.5 \\
F3 & 67.5 & 25 & 7.5 \\
\hline
\end{tabular}




\section{Results and Discussion}

\subsection{The Comprehensive Performance of the Four Groups}

\section{$A, B, C$ and $D$}

The grouping statistics of the six parameters are shown in Fig. 1.

According to Fig. 1, for the stable penetration rate and total porosity, the improvement in group $\mathrm{C}$ is obvious, reflecting that the improved material in group $\mathrm{C}$ has the significant improvement in the stable penetration rate and total porosity. Then, for aeration porosity, group B has the larger values. However, the values of each group don't change significantly with the increase in the adding ratio, which reflects these four improved materials don't significantly improve the aeration porosity. Besides, for $\mathrm{pH}$, the values of these four groups are not much different and there is no obvious change with the increase of the addition ratio. Moreover, the values of salt content of $C$ and $D$ groups are larger than $A$ and B groups. Finally, group $\mathrm{C}$ has the obvious advantage in organic matter content, which reflects the improved material in group $\mathrm{C}$ has higher organic content.

According to the test data, the comprehensive score $\beta$ of greening soil for each group of test samples were calculated in this section, as shown in Table 4.

According to the calculation results, the two major groups A and $\mathrm{B}$ using diatomite and blast furnace slag improved materials were unqualified. The two major groups $\mathrm{C}$ and $\mathrm{D}$ using sawdust and mushroom residue were qualified. Moreover, about the score of each item, all items in the C2 and C3 groups have a score of 3 or more, and $\beta$ values were 26 and 27, respectively. The improvement effect of these two groups was the best. Finally, the three added materials of diatomite, blast furnace slag and mushroom residue were discarded. Meanwhile, the C2 and C3 groups were
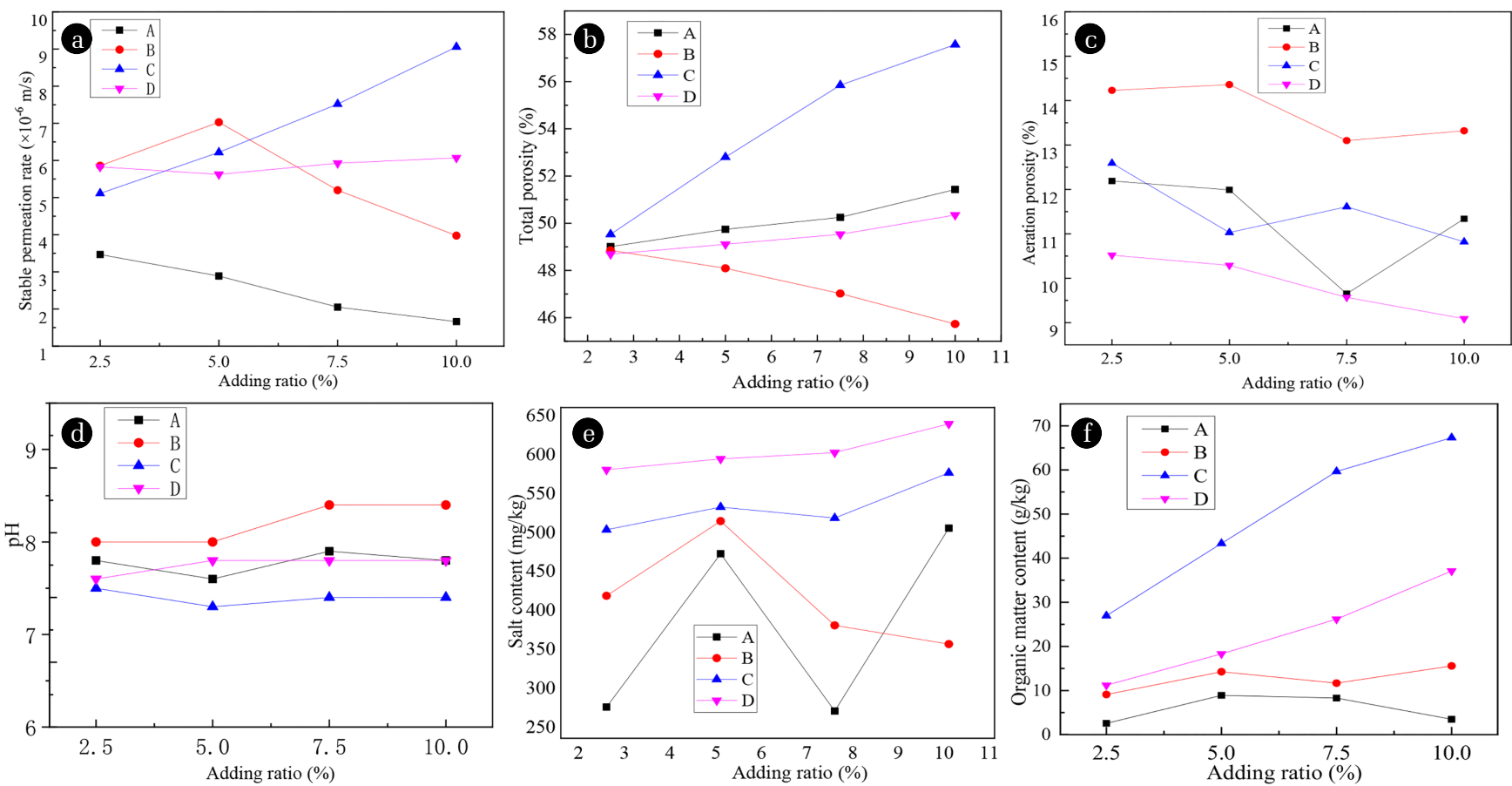

Fig. 1. Test data of various parameters in groups $A, B, C$ and D.

Table 4. Grades and $\beta$ Calues of the Greening Soil in Groups A, B, C and D

\begin{tabular}{|c|c|c|c|c|c|c|c|c|c|c|c|c|c|c|c|c|c|}
\hline Group & $v$ & $n$ & $n_{t}$ & $\mathrm{pH}$ & $w_{s}$ & $w_{o}$ & $\beta$ & $?$ & Group & $v$ & $n$ & $n_{t}$ & $\mathrm{pH}$ & $w_{s}$ & $w_{o}$ & $\beta$ & $?$ \\
\hline A1 & 2 & 3 & 4 & 3 & 5 & 1 & 18 & $x$ & C1 & 2 & 3 & 4 & 3 & 5 & 4 & 21 & $\sqrt{ }$ \\
\hline A2 & 2 & 3 & 4 & 3 & 5 & 1 & 18 & $\times$ & $\mathrm{C} 2$ & 4 & 5 & 4 & 3 & 5 & 5 & 26 & $\sqrt{ }$ \\
\hline A3 & 1 & 4 & 2 & 3 & 5 & 1 & 16 & $\times$ & C3 & 5 & 5 & 4 & 3 & 5 & 5 & 27 & $\sqrt{ }$ \\
\hline A4 & 1 & 4 & 4 & 3 & 5 & 1 & 18 & $x$ & $\mathrm{C} 4$ & 5 & 1 & 3 & 3 & 5 & 5 & 22 & $\sqrt{ }$ \\
\hline B1 & 3 & 2 & 4 & 2 & 5 & 1 & 17 & $x$ & D1 & 3 & 2 & 3 & 3 & 5 & 1 & 17 & $x$ \\
\hline B2 & 4 & 2 & 4 & 2 & 5 & 2 & 19 & $x$ & D2 & 3 & 3 & 3 & 3 & 5 & 2 & 19 & $\sqrt{ }$ \\
\hline B3 & 2 & 2 & 4 & 1 & 5 & 1 & 15 & $x$ & D3 & 3 & 3 & 2 & 3 & 5 & 4 & 20 & $\sqrt{ }$ \\
\hline B4 & 2 & 2 & 4 & 1 & 5 & 2 & 16 & $x$ & D4 & 4 & 4 & 2 & 3 & 5 & 5 & 23 & $\sqrt{ }$ \\
\hline
\end{tabular}

Where " $\times$ " means unqualified, and " $\sqrt{ }$ " means qualified. 
determined to be the optimal groups.

Therefore, according to the evaluation criterion, the two unqualified improved materials, diatomite and blast furnace slag were discarded, and mushroom residue and sawdust were qualified improved materials. At the same time, sawdust is the better improved material than mushroom residue as improved materials based on the scores of each item. Moreover, two better addition ratios of sawdust were obtained. It effectively demonstrated the superiority of the evaluation criterion that it could quickly evaluate the comprehensive performance of green soil. However, the comprehensive performance of green soil was neglected in previous researches, and only one or two factors were considered.

\subsection{Comprehensive Performance Test of Groups $E$ and $F$}

The grouping statistics of each characteristic parameter of groups $\mathrm{E}$ and $\mathrm{F}$ are shown in Fig. 2.

It could be seen from the Fig. 2 that for the stable penetration rate and total porosity, the values of the addition ratio of $7 \%$ are larger than the values of $5 \%$, which again reflects sawdust could effectively improve the penetration rate and total porosity. Besides, for the aeration porosity and $\mathrm{pH}$, the values of $7 \%$ adding ratio are not much different from the values of $5 \%$, which reflects sawdust has little effect on aeration porosity and $\mathrm{pH}$ of soil. Moreover, for salt content, the values of adding ratio of $5 \%$ are larger than the values of $7 \%$. That's because the soil samples with the addition ratio of $5 \%$ have more silt soil and sand than the soil samples with $7 \%$. Finally, for the organic matter content, sawdust contains a lot of organic matter, so it's not difficult to understand that the organic matter content of adding ratio of $7.5 \%$ is greater than the value of $5 \%$.

According to the experimental data, the comprehensive score $\beta$ of green soil of each group of samples were calculated, as shown in Table 5 .

The result shows that the scores of $\beta$ were same when the amount
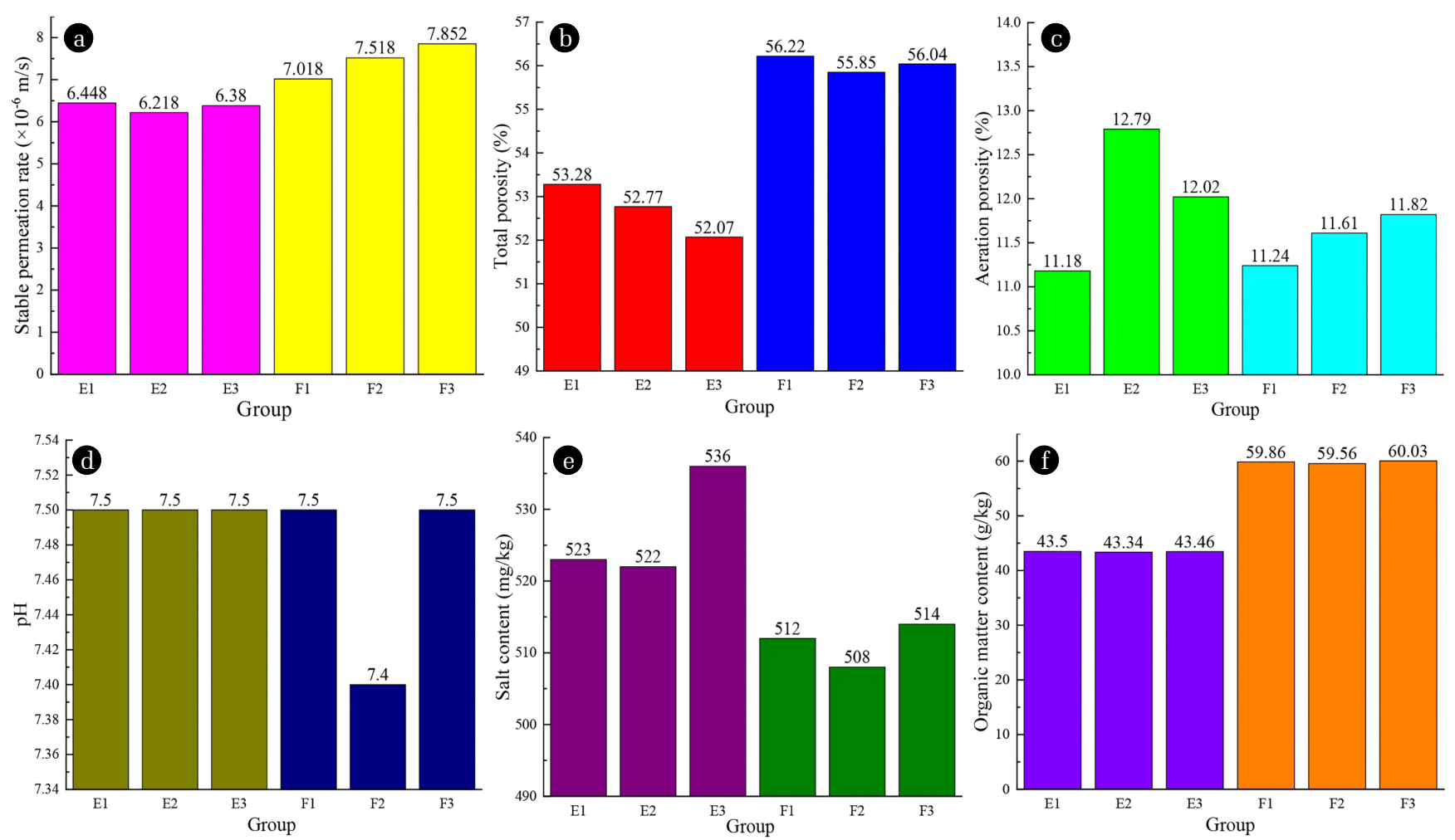

Fig. 2. Grouping statistics of each characteristic parameter of groups $E$ and $F$.

Table 5. Grades and $\beta$ Values of the Green Soil in Groups $E$ and $F$

\begin{tabular}{|c|c|c|c|c|c|c|c|c|}
\hline Group & $v$ & $n$ & $n_{t}$ & pH & $w_{s}$ & $w_{o}$ & $\beta$ & $?$ \\
\hline $\mathrm{E}_{1}$ & 4 & 5 & 4 & 3 & 5 & 5 & 26 & $\sqrt{ }$ \\
\hline $\mathrm{E}_{2}$ & 4 & 5 & 4 & 3 & 5 & 5 & 26 & $\sqrt{ }$ \\
\hline $\mathrm{E}_{3}$ & 4 & 5 & 4 & 3 & 5 & 5 & 26 & $\sqrt{ }$ \\
\hline $\mathrm{F}_{1}$ & 5 & 2 & 4 & 3 & 5 & 5 & 24 & $\sqrt{ }$ \\
\hline $\mathrm{F}_{2}$ & 5 & 5 & 4 & 3 & 5 & 5 & 27 & $\sqrt{ }$ \\
\hline $\mathrm{F}_{3}$ & 5 & 2 & 4 & 3 & 5 & 5 & 24 & $\sqrt{ }$ \\
\hline
\end{tabular}


of sawdust was $5 \%$. Meanwhile, the change of the proportion of medium sand had little effect on the improvement effect. When the amount of sawdust was $7.5 \%$, the change of the portion of medium sand made the total porosity of group F1 and group F3 exceed the upper limit, then reduced the improvement effect. Eventually, group F2 had the highest comprehensive index $\beta$ value and the best soil quality.

The new green soil obtained on the basis of the evaluation criterion could meet the requirements in terms of permeability, soil fertility, $\mathrm{pH}$ and salt content, which has the good comprehensive performance. Finally, the new compound green soil was prepared according to silt soil: medium sand: sawdust $=72.5 \%$ : $20 \%: 7.5 \%$.

\subsection{Comparative Analysis of Properties of New Compound Greening Soil and Other Existing Soil}

According to the mechanism of action of the sponge city, the effectiveness of the compound greening soil is mainly achieved through three characteristic parameters: penetration rate, maximum water holding capacity and field water holding capacity.

Firstly, the penetration rate could determine the speed at which rainwater seeps. The greater the penetration rate, the faster the rainwater seeps. Then, the maximum water holding capacity could determine the ability of green soil to store water. The greater the maximum water holding capacity, the stronger the ability of the green soil to store rainwater, and the more beneficial it is for rainwater control. Moreover, the difference between the maximum water holding capacity and field water holding capacity could determine the ability of the green soil to retain rainwater. The greater the difference, the stronger the ability to retain rainwater, which could stagger the peak of rainwater runoff to avoid flooding.

To analyze the efficiency advantages of the new compound greening soil prepared in this research, it was compared that the three characteristic parameters of the new compound green soil with the existing soil.

The new composite greening soil was compared with the soil of the current Chenshan Botanical Garden [40], Shanghai urban green soils [41], as shown in Table 6 .

According to Table 6 , the penetration rate of compound green soil was $9.22 \times 10^{-6} \mathrm{~m} / \mathrm{s}$, in contrast, the penetration rate of soil in Chenshan Botanical Garden and Shanghai urban area were 0.98 $\times 10^{-6} \mathrm{~m} / \mathrm{s}$ and $0.98 \times 10^{-6} \mathrm{~m} / \mathrm{s}$, respectively. Therefore, the penetration rate of the new compound green soil was significantly higher than the current penetration rate of the green soil in Shanghai, which ensures that rainwater could seep quickly. In addition, the difference between maximum water holding capacity and field water holding capacity of the new compound greening soil (101.30 $\mathrm{g} / \mathrm{kg}$ ) was significantly higher than the current status of greening soil in Shanghai $(31.20 \mathrm{~g} / \mathrm{kg}$ ), and the ability to accumulate and retain rainwater were significantly higher than the existing urban greening soil. Moreover, the new green soil meets the requirements of the sponge city for soil $\mathrm{pH}$, fertility and salt content. However, the existing green soil in Shanghai has the defects such as low permeability and low organic matter content, which cannot meet the comprehensive performance requirements of the green soil in the sponge city.

Based on the comparison and analysis of permeation rate, the difference between maximum water holding capacity and field water holding capacity and other data, the new compound green soil has superior permeability and water holding capacity. Therefore, it means that the new compound soil can improve the control of rainwater, reduce runoff and play an important role in the construction of sponge cities.

\subsection{Application Prospect of the Compound Greening Soil}

Rainwater management measures and low-impact development technologies have been developed in developed countries such as Europe and the United States since the 1990s. In recent years, the Chinese government has issued a series of policies, plans, guidelines and other documents, proposing to vigorously develop sponge city construction. Moreover, many cities have begun to build sponge cities as pilot cities.

The design of the new compound greening soil serves the construction of the sponge city. Compared with the existing soil, the result shows the new greening soil not only meets the technical requirements of the sponge city for soil, but also has excellent permeability and water retention. Therefore, the soil can play a role in reducing runoff and increasing the annual total runoff control rate, which could help strengthen the management of rainwater.

In the field of application, the new compound greening soil could be used for many low-impact development measures for sponge cities such as green roofs, sunken green spaces, biological retention facilities, infiltration ponds, rainwater wetlands, planting ditches and vegetation buffers [42-44]. Therefore, the greening soil has many application fields and large demand.

In terms of soil preparation, the compound greening soil is composed of silt soil, sand and sawdust. As we all know, the raw materials are easily obtained, the economic cost is low, and it is convenient for large-scale production.

Finally, the needs of society and urban development, the support of national policies, outstanding self-efficiency and many applica-

Table 6. Comparison of Permeability and Water Holding Capacity

\begin{tabular}{|c|c|c|c|c|c|}
\hline Soil & $\begin{array}{l}\text { Penetration rate } \\
(\mathrm{m} / \mathrm{s})\end{array}$ & $\begin{array}{l}\text { Water holding capacity } \\
\text { (g/kg) }\end{array}$ & $\begin{array}{l}\text { Field water holding capacity } \\
\text { (g/kg) }\end{array}$ & $\begin{array}{c}\text { Difference } \\
(\mathrm{g} / \mathrm{kg})\end{array}$ & $\begin{array}{c}\text { Bulk density } \\
\left(\mathrm{g} / \mathrm{cm}^{\mathbf{3}}\right)\end{array}$ \\
\hline $\begin{array}{l}\text { Soil of Chenshan } \\
\text { Botanical Garden }\end{array}$ & $0.98 \times 10^{-6}$ & 336.25 & 305.05 & 31.20 & 1.42 \\
\hline $\begin{array}{l}\text { Green soil in Shanghai } \\
\text { urban area }\end{array}$ & $0.97 \times 10^{-6}$ & 379.46 & 347.79 & 31.67 & 1.31 \\
\hline $\begin{array}{l}\text { The new compound } \\
\text { green soil }\end{array}$ & $9.22 \times 10^{-6}$ & 417.80 & 316.50 & 101.30 & 1.17 \\
\hline
\end{tabular}


tion facilities all indicate that the prospects for the application of new composite greening soils are considerable.

\section{Conclusions}

(1) To quickly evaluate the quality of green soil of green soil samples in sponge city, an evaluation criterion of green soil was designed, and a comprehensive quantitative index $\beta$ was defined.

(2) When the characteristics of permeability, water holding capacity, $\mathrm{pH}$, aeration porosity and fertility were comprehensively taken into account, a new type of compound greening soil was deployed to solve the current existing greening soil that could not meet the requirements of sponge city construction. Its proportion is silt soil: medium sand: sawdust $=72.5 \%$ : 20\%: $7.5 \%$.

(3) Based on the comparison with other existing soils, the new compound green soil had apparent advantages under multi-angle analysis, and played a role in the construction of sponge cities with advantages such as high permeability and high water-holding capacity.

(4) The new greening soil has wide application fields and large demand. Meanwhile, the country has vigorously developed sponge cities, and the raw materials are cheap and easy to obtain. Therefore, the soil has considerable application prospects.

\section{Acknowledgment}

This investigation was supported by the National Natural Science Foundation of China (projects No. 41672274 and 41002093); the Fundamental Research Funds for the Central Universities; the Natural science foundation of Shanghai (project No. 14ZR1442800); Opening fund of State Key Laboratory of Geohazard Prevention and Geo-environment Protection (Chengdu University of Technology) (projects No. SKLGP 2014K013).The authors are extremely grateful for the financial support from these five organizations.

\section{Author Contributions}

Z L. (Master Student) conducted all the experiments and wrote the manuscript. L.Z.C. (Master Student) and Y.T.L. (Professor) as well Y.P. (Professor) revised the manuscript.

\section{References}

1. Wang M, Martin, E, Shaheen S. Carsharing in Shanghai, China: Analysis of Behavioral Response to Local Survey and Potential Competition. Transp. Res. Rec. 2012;2319(1):86-95.

2. Zhong S, Qian Y, Zhao C, Leung R, Yang X-Q. A case study of urbanization impact on summer precipitation in the Greater Beijing Metropolitan Area: Urban heat island versus aerosol effects. J. Geophys. Res. 2015;120(20):10903-10914.

3. Wu M, Zhao J, Lin C, et al. Research progress on purification of rain runoff by permeable concrete pavement. Mod. Chem. Ind. 2017;37(10):25-28, 30.

4. Chaohsien L, Gao A, Huang E. Enlightenment of rainwater management in foreign countries to sponge city construction in China. Water Resour. Prot. 2016;32(1):42-45, 50.

5. Jiang Y, Zevenbergen C, Ma Y. Urban pluvial flooding and stormwater management: A contemporary review of China's challenges and "sponge cities" strategy. Environ. Sci. Policy. 2018;80:132-143.

6. Jun X, YongYong Z, LiHua X, et al. Opportunities and challenges of the Sponge City construction related to urban water issues in China. Sci China-Earth Sci. 2017;60(4):652-658.

7. Xia C. Discussion on the Concept of Sponge City Construction in General Layout Design. For. Investigation Des. 2019;1:20-21.

8. Ishimatsu K, Ito K, Mitani Y, et al. Use of rain gardens for stormwater management in urban design and planning. Landsc Ecol. Eng. 2017;13(1):205-212.

9. Amirbeiki TF, Rezaeian M, Emadian RSZ. Sunken courtyards as educational environments: Occupant's perception and environmental satisfaction. Tunn. Undergr. Sp. Technol. 2018;78: 124-134.

10. Wu S, Wen B, Zhou C. Research on Site Selection and Design Points of Sunken Green Space Based on Sponge City Theory. J. Chem. Inf. Model. 2017;53(9):1689-1699.

11. Davis AP, Hunt WF, Traver RG, Clar M. Bioretention technology: Overview of current practice and future needs. J. Environ. Eng. 2009;135(3):109-117.

12. Sansalone J, Kuang X, Ranieri V. Permeable pavement as a hydraulic and filtration interface for urban drainage. J. Irrig. Drain. Eng. 2008;134(5):666-674.

13. Fassman-Beck E, Voyde E, Simcock R, Hong YS. 4 Living roofs in 3 locations: Does configuration affect runoff mitigation? J. Hydrol. 2013;490:11-20.

14. Li J, Deng C, Li Y, Li Y, Song J. Comprehensive Benefit Evaluation System for Low-Impact Development of Urban Stormwater Management Measures. Water Resour. Manag. 2017;31(15): 4745-4758.

15. Zhou K, Li P, Shi M. Simulation Study on Road Permeability Pavement Construction of Xiangyang City Under the Concept of Sponge City. Bull. Sci. Technol. 2019;35(8):82-85.

16. Yang JL, Zhang GL. Water infiltration in urban soils and its effects on the quantity and quality of runoff. J. Soils Sediments. 2011;11(5):751-761.

17. Martínez F, Casermeiro MA, Morales D, Cuevas G, Walter I. Effects on run-off water quantity and quality of urban organic wastes applied in a degraded semi-arid ecosystem. Sci. Total Environ. 2003;305(1-3):13-21.

18. Yang J, Zhang G, Yuan D. Characteristics of water infiltration in urban soils of Nanjing City. J. Appl. Ecol. 2008;19(2):363-368.

19. Zhao L. Situation and Countermeasures of Urban Street Greening Tree Soil of TEDA of Tianjin. Tianjin. Agric. Sci. 2017;023(002):101-103

20. Zhu X, Zhang Y, Yang S. Spatial variability of soil nutrients in the core area of Beijing. J. Fujian Agric. For. Univ. 2018;47(5):580-587. 
21. Wei Z, Zhou G, Hu Q. Research Status on Utilization of Edible Fungus Residues. China Edible Fungi. 2010;29(5):3-6.

22. Tian B, Shi L, Wang X, Liu D. Effect of Spent Mushroom Compost on Soil Quality and Turf Growth. Chinese J. Grassl. 2011;33(5):101-106.

23. Wei W, Tang N, Li T. Field Survey and Improvement for Soil Infiltration Characteristics of Urban Green Land in Shanghai. Water Purif Technol. 2011;30(4):78-83.

24. Zhu M, Liao J, Chen G, Wang J, She N. Water resources production. WATER Resour Prot. 2013;29(3):25-33.

25. Shen J, LI B, Hu F, Jiang X. Effect of Waste Diatomaceous Earth on Soil Fertility Improvement. J. Zhejiang Shuren Univ. 2011;11(3):15-18.

26. Chu Z. Study on artificial simulation test of retention effect of rainwater biological retention system. J. Shengli Coll. China Univ. Pet. 2017;31(1):34-37.

27. Jing Y, Li J, Mei Y, et al. Design and performance of urban sponges in red soil: improvement of physical and chemical properties. J. Water Clim. Chang. 2020;(3):1-13.

28. Zhu J, He H, Li H, et al. Characteristics of Soil Bulk Density and Soil Water-Holding Capacity in Alpine Meadow Under Grazing Gradients. Res Soil Water Conserv. 2018;25(5):66-71.

29. Cardoso EJBN, Vasconcellos RLF, Bini D, et al. Soil health: Looking for suitable indicators. What should be considered to assess the effects of use and management on soil health? Sci Agric. 2013;70(4):274-289.

30. Li H, Parent LE, Karam A, Tremblay C. Potential of Sphagnum peat for improving soil organic matter, water holding capacity, bulk density and potato yield in a sandy soil. Plant Soil. 2004;265(1-2):355-365.

31. Prince George's County, Maryland. The bioretention manual[M]. Department of Environmental Resources, Prince George's County, 2009.

32. Xue L, Li Y, Qu M, Yan S, Wang X. Soil properties and water holding capacities of Michelia maclurei, Schima superba and Castanopsis fissa stands. Chinese J. Appl. Ecol. 2005;16(9):
1623-1627.

34. Liu H, Zhao Y, Zhou Y, Lin C, Zhang J. Research on Comprehensive Utilization Technology of Chemical Waste Diatomite. Anhui Chem. Ind. 2010;36(B09):61-64.

35. Liu H, Zhao Y, Zhou Y, Chang L, Zhang J. Removal of gaseous elemental mercury by modified diatomite. Sci. Total Environ. 2019;652:651-659.

36. Sheen YN, Zhang LH, Le DH. Engineering properties of soil-based controlled low-strength materials as slag partially substitutes to Portland cement. Constr. Build Mater. 2013;48: 822-829.

37. Khan S, Khan H. Improvement of mechanical properties by waste sawdust ash addition into soil. Jordan J. Civ. Eng. 2016;10(1):18-28.

38. Keramatikerman M, Chegenizadeh A, Nikraz H. An investigation into effect of sawdust treatment on permeability and compressibility of soil-bentonite slurry cut-off wall. J. Clean Prod. 2017;162:1-6.

39. Li F, Wang H, Zhang Q. Effect of mushroom residue on soil property and crop and research progress in its recycling. Rev China Agric. Sci. Technol. 2015;17(3):100-106.

40. Dai H. Research status of utilization of edible fungus residue. Agric. Dev. Equip. 2015;167(11):71.

41. Wu H, Fang H, Peng H. Analysis of soil physical properties of Shanghai Chenshan Botanical Garden in a typical new green space. J. Soil Water Conserv. 2012;26:85-90.

42. Wu H. Study on Soil Physical Properties of Green Belts in Central Urban Area of Shanghai. Soils. 2018;50(1):155-161.

43. Chen Y, Samuelson HW, Tong Z. Integrated design workflow and a new tool for urban rainwater management. J. Environ. Manage. 2016;180:45-51.

44. Wan Y, Gai X. Renovation of urban waterlogging sites based on sponge city concept. Water Wastewater Eng. 2017;43(3):55-58.

45. Zhang S. Construction of "Sponge City" Based on Comprehensive Utilization of Urban Rain and Flood Resources. Constr. Technol. 2015:26-28. (Published online) 